\title{
A Periodicals Access Survey in a University Library
}

\section{William Watson}

Unavailability of periodicals when they are needed has been a recurrent complaint about the University of British Columbia Library system. In most branches, periodicals are allowed to be borrowed after they have been on the shelf for a month, excepting a few anchored sets. To some users this practice is quite wrong, provoking protests such as, "I never get the issue I want," and, "We should be able to count on finding every issue of every journal available on the library shelves." We have considered the possibility of reducing or eliminating circulation of periodicals, but we know there are many readers who would be seriously inconvenienced by limited opportunity to use them in other locations and over an extended period of time.

To consider this specific question, whether or not to continue to circulate periodicals, as well as to determine whether there were ways in which access to periodicals might be enhanced, the university librarian appointed a Committee on Access to Periodicals. The committee recommended that a survey was needed to determine the actual extent of unavailability of periodicals.

\section{THE FIRST SURVEY, NOVEMBER 1983}

Specifications for the first survey, initially the only one planned, were that it would take place during the busiest part of the fall session. It would measure the availability of a representative sample of periodicals across the library system. It would not be an opinion survey but a practical determination of what part of the sample was available for immediate use, what was available in due course, and what was not available except through interlibrary loans.
After some trial and error it was found that workable lists could be computerproduced and the lists could be completed by hand by members of the committee and two or three volunteers. Lists of three hundred active subscriptions each were run for 13 locations and lists of one thousand titles for two other locations. Entries included call number (except for a few uncataloged items), title, frequency (where it had been established), and a brief, incomplete, statement of holdings. The librarians supplied random numbers identifying the issue to be searched for each title listed. Because the holdings statements were kept brief they did not always provide sufficient information for a decision as to what would be a valid search.

Librarians were asked in each case to mark down from a random-number table or from dice a number specific enough for a searcher. They were to prefer a volume and issue number to a date whenever there was a choice. In some cases, particularly periodicals with numerous volumes and numbers per year, where the random number would offer a choice from two or more issues, they were to choose the most recent one. And if the holdings seemed to be largely complete (no more than three "missing" statements) the librarians would pick any suitable number including that of a missing item. Where there were more gaps in the holding statements (more than three "missing" statements) the choice of an issue to be searched would be confined to those the library would be expected, from the evidence, to have. Where the information provided in the holdings statements was wanting, or incomplete, or contradictory, that entry was to be eliminated from the search.

The intent was to focus on periodicals

William Watson is assistant university librarian at the University of British Columbia, Vancouver, B.C., Canada V6T $1 Y 3$. 
from the last 10 years, still on the active subscription lists, which might reasonably be assumed by a person capable of using the library catalogues to be held by the library. There was an implicit assumption that material in backfiles from more than 10 years ago would not be less available than the more recent and more heavilyused periodicals.

The lists coded by the librarians were provided with columns representing places or conditions believed to be likely for the periodicals. Searchers were told how to interpret the coding and asked to write on the lists any information they thought would help to explain what they had discovered in the searching.

During the period October 31 to November 6 inclusive, the lists were farmed out to the locations and the division heads were asked to make sure that the searching was completed during those seven days. Except for a few problem entries, this condition was satisfied.

\section{SURVEY 1 FINDINGS AND CONCLUSIONS}

The tabulated findings of the November survey are shown in Table 1. Explanation of the categories is given in Appendix A.

The committee made several observations based on the findings and their interpretation.

One observation was that 78.45 percent of the material was on the shelves readily accessible to the user. And another 7.62 percent was accessible at the time with staff aid. These two general categories accounted for 86.07 percent of the periodicals surveyed.

TABLE 1

AVAILABILITY OF PERIODICALS, NOVEMBER 1983 SURVEY

\begin{tabular}{lcc}
\hline & Number & Percent \\
\hline Available directly & & \\
On shelf bound & 2,974 & 55.16 \\
On shelf unbound & 1,256 & 23.29 \\
\cline { 2 - 3 } & 4,230 & 78.45 \\
Available indirectly & 301 & 5.58 \\
In sorting area, etc. & 110 & 2.04 \\
In another division & 411 & 7.62 \\
& $(4,641)$ & $(86.07)$ \\
(Cumulative subtotal) & & \\
Available within a fortnight & 70 & 1.3 \\
On shelf after first search & 23 & 0.43 \\
Misshelved & 115 & 0.13 \\
In the bindery & 7 & 1.8 \\
In process in LPC & 97 & 0.04 \\
On loan & 2 & 0.02 \\
On hold & 1 & 5.84 \\
In use in the library & 315 & $(91.91)$ \\
& $(4,956)$ & \\
(Cumulative subtotal) & & 0.37 \\
Not available & 20 & 0.56 \\
Declared missing & 30 & 4.15 \\
Retain current issues only & 224 & 1.43 \\
Not receivedt & 77 & 0.26 \\
Do not hold & 14 & 1.32 \\
Lapsed & 71 & 8.09 \\
Not found & 436 & $(100.00)$ \\
& $(5,392)$ &
\end{tabular}

"Material is at the bindery itself for two weeks and can be rushed if circumstances warrant the additional costs. Prior to going to the bindery and after return, the material is waiting to be processed for varying periods of time. Again, it can be retrieved if necessary, but at some cost. Most of the time, unless the item wanted has just been dispatched to the bindery, the statement that it can be produced for a user within two weeks is valid, but in practice it is not advertised.

†Much of this "not received" material will arrive and be made available in due course. 
Another observation was that if the potential user was able to wait a short time, anywhere from an hour to two weeks, another 5.84 percent of the periodicals could be obtained. The cumulating subtotal of the available category was 91.91 percent of the sample.

The most distressing observation was that 8.09 percent of the periodicals could not be located. Some of them-perhaps one half-would come along later, but at least at the time all were inaccessible. (On interlibrary loan they would take from one to six weeks to be delivered, depending on the source.)

Some 4 percent of the sample had either disappeared for reasons unknown, or were never part of UBC's holdings, or were discarded as no longer useful. It was observed that some would turn up as mysteriously as the way they went missing.

The committee, lacking a yardstick, did not determine whether there were any unusual problems to tackle. Whether 1.32 percent not found and 0.37 percent declared missing are high figures for these categories was unclear. (We would appreciate receiving any objective comparisons.)

Three conclusions were reached. The first was that with only 1.85 percent of the material in the hands of another borrower or being held for another borrower, the circulation of periodicals could not be considered a serious obstacle to access to periodicals.

Another was that the staff needed regu- lar reminding that as many issues as possible should be on the open shelves where they are directly accessible to users rather than behind the scenes where they can be reached only with help.

The third conclusion was that a second, more limited survey was wanted, similar to the first, but focusing not on a random cross section of periodicals but on a careful selection of most used periodicals. This additional survey was conducted in March 1984.

\section{THE SECOND SURVEY, MARCH 1984}

On March 5 and 6, 1984, two hundred of the most heavily used periodicals held by the science division of the main library were tested for availability. That division provides a reference service for the sciences excepting life sciences, mathematics, forestry, and agriculture, all covered by other branches. The three science reference specialists each chose 65 to 70 titles which their experience showed to be most heavily used. Coincidentally the total arrived at was precisely two hundred.

For each of the two hundred titles, one set of randomly selected issues from the period 1974 to 1983 inclusive, and another set from the year 1983 only, were searched. The results of the second survey are shown in table 2.

\section{CONCLUSIONS FROM SURVEY 2 FINDINGS}

Three categories from the 1983 sample

TABLE 2

AVAILABILITY OF HEAVILY USED SCIENTIFIC PERIODICALS, MARCH 1984 SURVEY

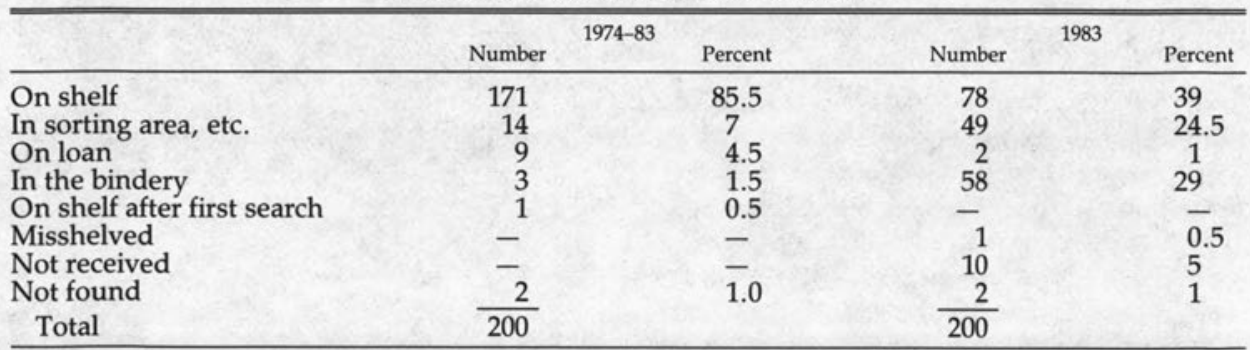

Notes: The items on the open shelves were directly available to the users, while the ones "in sorting area, etc." (local prebindery, morgue, storage) could be located with staff help. Those on loan, in the bindery, on the shelf after the first search, and misshelved, would become available in due course, most of them within a fortnight. The three items from the 1974-83 set found to be in the Bindery were all 1983 issues. 
call for special comments. The ten items "not received" were made up of five which had already been claimed and five known to be slow to arrive. One of those claimed involved a single missing issue, subsequent issues having arrived, while the others represented subscriptions that had run into problems needing to be resolved. There were 58 items in the bindery and another 49 available only with staff assistance. Of the latter group, many were in the science divisional prebindery. Altogether, some 85 items from a sample of 200 were not immediately or not directly available because of binding. Of the 85 , about 55 were retrievable with staff help from within the division or by being "rushed" from the Library Processing Centre.

To interpret the results of this science survey in the context of the system-wide survey of November, it is best to consider the 1974-83 sample and the 1983 sample separately. The 1974-83 set is directly comparable with material covered in the earlier survey except that it was chosen as most heavily used while the earlier survey was a general cross-section.

It is remarkable that 85.5 percent of the most-used science periodicals were on the open shelves available for use, comparing favorably with the 78.45 percent of the earlier sample. Another 7 percent were available with staff aid, and 6.5 percent would become available after a wait. One percent of the sample could not be found.

Again, the committee concluded that circulation did not appear to be a significant barrier to access, as only 4.5 percent of the most-used periodicals were out on loan.

From the 1983 set, 39 percent of the issues in the sample were directly available and 24.5 percent were available with staff aid, for a total of 63.5 percent available within a few minutes. This proportion is considerably less than the 86.07 percent quickly available in the November survey. The difference is entirely accounted for by the 29 percent of the material "in the bindery" in the science survey.

In the remaining categories there were no significant differences between the results of the earlier survey and those of the survey of the 1983 science sample.
On material out for binding, it should be noted that the science survey was made at a time of year when a great deal of binding is done, just when the preceding year's indexes have arrived and the volumes are complete. As the head of the science division observed, "While there is no 'good time' for binding, this may well be the best time." Users who read issues as they arrive on the shelves have already done so, while those who approach journals through abstracting and indexing services will be waiting for the abstracts to arrive.

\section{GENERAL CONCLUSIONS}

The committee undertook several other related investigations and came up with twenty recommendations, which can be summarized as:

- No change in circulation policy for periodicals was indicated.

- Better physical facilities should be provided for periodicals as soon as feasible.

- Improvements in housekeeping arrangements, computing systems, staff training, prebindery operations, and

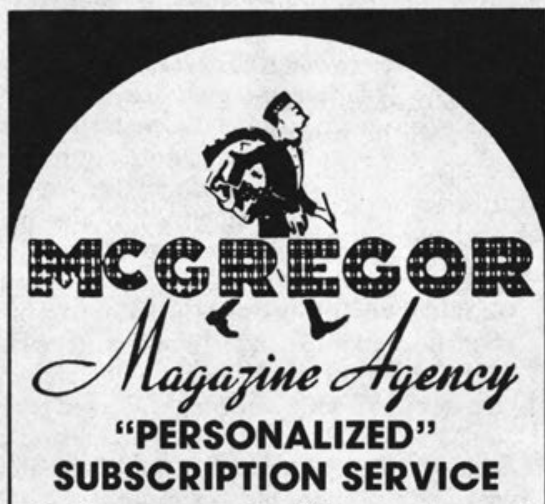

McGregor can simplify complex and time consuming problems of periodical procurement involving research, ordering, payments, renewals and record keeping. Prompt courteous service has been a tradition with McGregor since 1933.

Call or write for catalog today $815 / 734-4183$

MCGREGOR MAGAZINE AGENCY Mount Morris, Illinois 61054 
work priorities would enhance the availability of periodicals.

The November survey called for about a person/month's staff time and the March survey for four person/days' time. The committee considered that the time had been well spent in providing a good working answer to the specific question on circulation and the general question of periodical availability. They hope, at the same time, that it will be ten years before another survey is wanted.

\section{APPENDIX A: PERIODICALS ACCESS SURVEY-MEANINGS OF THE CATEGORIES}

1. On the shelf-bound. The item was located on the open shelf in the stacks accessible to the public.

2. On the shelf-unbound. Found on the shelf or in the box where unbound material is kept. In the case of unbound government periodicals in the main library, the proper place is the government publications division. In the case of other unbound periodicals, locations are the humanities and social sciences periodicals area or the science periodicals area.

3. In the sorting area, a divisional prebindery or morgue, in storage, or in any area where items can normally be located only with staff help.

4. On loan. The loan is recorded either on the automated system or in the manual circulation file.

5. In the bindery, including the Library Processing Centre Prebindery. Not in a local prebindery, for which see 3 above, but unavailable for immediate consultation or loan.

6. Identified as "missing." The item had been traced previously and not being found had been listed as missing prior to the survey. It may be long overdue or unaccountably missing. Whether a replacement copy has been ordered or not is normally shown on the circulation fiche.

7. On hold. Being held aside for another borrower. Usually such an item can be briefly consulted by the seeker, but not borrowed until the other user has had an opportunity to obtain it.

8. On the shelf after the first search. This one was not on the shelf when first sought, but it was there by the time a second search was made usually three or four days later. It was probably in use or waiting to be reshelved after use.

9. Misshelved. Located, but not where it was meant to be found. Often this sort of material can be spotted by experienced staff members.

10. In another division. The item was found to be in another division than the one where it was sought. This category includes divisional reference collections in the main library. It also includes material which has been transferred from one location to another, and material whose current issues are kept in one location, bound volumes in another. In almost all cases the information on location in the microcatalogue is correct.

11. Not received. This category includes material that has not, or not yet, arrived, though it might have been expected to be there. If the library has or had a subscription which appears to cover the period represented by the number searched, it was considered a valid search. For numbers which would seem to belong to the latter part of 1983 , for instance, they would be considered fair game. If not checked in, such an item would be identified here as "not received." Probably more than half of the "not received" items will arrive in the next few months.

12. Do not hold. This category was used for items that turned out to be outside the scope of the holdings list. If the checklist was unspecific, or incorrect, or misleading about when the subscription began and if the item identified for searching was found to predate the actual subscription it was marked "do not hold." Similarly, if a backfile with lacunae was purchased and if the search was for an issue or volume missing from the set, the "do not hold" box was marked. Most items so identified cannot be expected to arrive.

13. Lapsed. This designation covers two main types of material: titles which went out of existence or for which the library subscription was cancelled; and those where the lapse seems to have escaped attention for an unknown reason. Most of the suspended and cancelled periodicals are properly identified in the microcatalogue. Where the lapse has been inadvertent and is just being discovered, it will not be reflected in the microcatalogue.

14. In process in the Library Processing Centre. The item has been checked in but not yet delivered to the shelf, or it has been removed for processing.

15. Library retains current issues only. Ephemera. This category covers newsletters and the like. The holdings that are maintained are from the current year, or the last two or three years, depending on a judgment that has been made as to their useful life. The statement is carried in the microcatalogue. 
16. Not found. This is the catch-all category to which an item is consigned whenever it cannot be located and no reason is determined. Presumably some items have been lost or stolen, others are in transit or in use. After time has been allowed for an item to turn up a decision is made whether to attempt to replace it. The gifts and exchanges unit may be able to obtain a free copy, or it may have to be purchased.

\section{Using Time-Series Regression to Predict Academic Library Circulations}

\section{Terrence A. Brooks}

Four methods were used to forecast monthly circulation totals in 15 midwestern academic libraries. In a test of one-month forecasting accuracy, the dummy regression method, a sophisticated forecasting method for cyclical data, exhibited the smallest average error. In a test of six-month forecasting accuracy the monthly mean method, a naive forecasting method for cyclical data, exhibited the smallest average error. Straight-line predictive methods, both naive or sophisticated, had significantly greater error in both accuracy tests. A remaining research question is, Why do naive forecasting methods outperform more sophisticated forecasting methods with monthly library circulation data in long-range forecasts? It is suggested that high levels of randomness in library-output statistics inhibit the performance of sophisticated forecasting methods.

\section{INTRODUCTION}

A time series is a chronological sequence of observations on a variable. ${ }^{1}$ An example from the field of librarianship of such a variable is circulation check-outs. Library circulation counts are commonly compiled on a daily basis and aggregated into monthly or semester reports. A series of these monthly counts is a chronological sequence of observations on the variable library circulation. Consequently, it is fair to conclude that the most typical type of statistical data libraries produce is timeseries data. Library literature, however, reveals little awareness of the ways that time-series data can be used for forecasting and planning.

Time-series regression techniques are regression procedures used to predict future values of a time series. They are unique only in that they use past values of a time series to predict future values of the same time series. This paper reports the application of two types of time-series regression to the problem of forecasting academic library circulation.

\section{FORECASTING}

"In library planning and decisionmaking, predictions are invariably required.",2 Despite Hamburg's statement, there has not been much theoretical work or practical application of forecasting methodologies to library statistics. This is in sharp contrast to the acceptance of forecasting in other disciplines. Forecasting, or trend analysis, is considered an integral part of scientific management and rational decision making. Makridakis and Wheelwright $^{3}$ describe forecasting as a tool that permits management to shield an organization from the vagaries of chance events and become more methodical in dealing with its environment. Like bureaucracies everywhere, academic libraries need tools that will enhance planning and rational decision making.

Filley and House ${ }^{4}$ would characterize most academic libraries today as third-

Terrence A. Brooks is assistant professor at the School of Library and Information Science, University of Iowa, Iowa City, Iowa 52242. 